(С) Коллектив авторов, 2021

Николаева Т.Н., Козлов В.В., Кожевникова Т.Н., Григорьева Е.А., Сосновская О.Ю., Чекнёв С.Б., Санин А.В., Пронин А.В.

Изучение иммунного ответа и состояния метаболизма

на экспериментальных моделях развития гиперлипидемии и метаболического синдрома

Федеральное государственное бюджетное учреждение «Национальный исследовательский центр эпидемиологии и микробиологии имени почетного академика Н.Ф. Гамалеи» Министерства здравоохранения Российской Федерации, 123098, г. Москва, Российская Федерация

\title{
Резюме
}

Введение. Иммунная система выполняет важную роль в патогенезе гиперлипидемии (ГЛ) и метаболического синдрома (МС). Метаболические дисфункции сопровождаются нарушениями кооперации, межклеточного взаимодействия различных звеньев иммунной системы. К ключевым патогенетическим факторам ГЛ и МС относятся изменение секреции медиаторов адипоцитов (адипонектина, лептина), провоспалительных и противовоспалительных цитокинов (ЦТ). Данные экспериментальных и клинических исследований свидетельствуют о взаимосвязи и взаимообусловленности клеточных иммунных реакций, медиаторов межклеточных взаимодействий и метаболических нарушений макроорганизма.

Цель исследования - изучение популяционного состава лимфоидных клеток селезенки, продукции цитокинов и функциональной активности лимфоцитов при экспериментальном моделировании МС и ГЛ.

Материал и методы. Эксперименты выполнены на мышах C57B1/6. Исследования проведены на 2 экспериментальных моделях МС и ГЛ, основанных на длительном выпаивании животных 20 \% водным раствором фруктозы с добавлением в корм холестерина и внутрибрюшинном введении мышам Полоксамера 407 соответственно.

Оценка субпопуляционного состава клеток селезенки мышей проведена методом проточной цитометрии. Определение лептина, адипонектина, инсулина, цитокинов интерлейкина(ИЛ)-15, ИЛ-22 в сыворотке крови мышей проводили методом ELISA с использованием коммерческих наборов. Пролиферацию лимфоцитов оценивали в реакции бласттрансформации (РБТЛ).

Результаты экспериментов при моделировании МС и ГЛ свидетельствуют об изменении популяционного состава селезенки (снижение содержания CD4 $4^{+}$и $\mathrm{CD}^{+}-\mathrm{T}-$-клеток, активация $\mathrm{CD}^{+} \mathrm{CD} 25^{+} \mathrm{Foxp} 3^{+}-$Treg-клеток), сопровождающимся снижением функциональной активности иммунокомпетентных Т-клеток и увеличением пролиферативной активности В-лимфоцитов, нарушением продукции ИЛ-15, -22, участвующих в липидном обмене, и о дисфункциональных изменениях медиаторов липидного и углеводного обмена (адипонектин, лептин, инсулин), что в совокупности является предпосылками для развития хронического воспаления - важнейшего патогенетического признака МС.

Заключение. Полученные данные по изменению иммунного ответа и состояния метаболизма подтверждают целесообразность поиска и скрининга иммунокорригирующих лекарственных средств, предназначенных для профилактики и лечения гиперлипидемии и симптомокомплекса МС, исходя из целенаправленного воздействия на ведущие звенья патогенеза метаболической болезни.

Ключевые слова: метаболический синдром; гиперлипидемия; адипонектин; лептин; экспериментальная модель; иммунный ответ; Treg-клетки; цитокины

Статья получена 07.04.2021. Принята в печать 16.06.2021.

Для цитирования: Николаева Т.Н., Козлов В.В., Кожевникова Т.Н., Григорьева Е.А., Сосновская О.Ю., Чекнёв С.Б., Санин А.В., Пронин А.В. Изучение иммунного ответа и состояния метаболизма на экспериментальных моделях развития гиперлипидемии и метаболического синдрома. Иммунология. 2021; 42 (4): $337-345$. DOI: https://doi.org/10.33029/0206-4952-2021-42-4-337-345

Финансирование. Исследование не имело спонсорской поддержки.

Конфликт интересов. Авторы заявляют об отсутствии конфликта интересов. 
Nikolaeva T.N., Kozlov V.V., Kozhevnikova T.N., Grigorieva E.A., Sosnovskaya O.Yu., Cheknev S.B., Sanin A.V., Pronin A.V.

\section{Study of the immune response and metabolism state using experimental models of hyperlipidemia and metabolic syndrome}

National Research Centre for Epidemiology and Microbiology named after the honorary academician N.F. Gamaleya of the Ministry of Health of the Russian Federation, 123098, Moscow, Russian Federation

\section{Abstract}

Introduction. The immune system plays an important role in the pathogenesis of hyperlipidemia (HL) and metabolic syndrome (MS). Metabolic dysfunctions are accompanied by disorders of cooperation, intercellular interaction of various parts of the immune system. The key pathogenetic factors of GL and MS are changes in the secretion of adipocyte mediators (adiponectin, leptin), pro-inflammatory and anti-inflammatory cytokines (CT). The data of experimental and clinical studies indicate the relationship and interdependence of cellular immune responses, mediators of intercellular interactions and metabolic disorders of the macroorganism.

The aim of this study was to estimate the population composition of spleen lymphoid cells, the production of cytokines and the functional activity of lymphocytes in 2 experimental models of MS and HL.

Material and methods. Experiments were performed on $\mathrm{C} 57 \mathrm{Bl} / 6$ mice. The studies were carried out on two experimental models of MS and GL, based on long-term feeding of animals with a $20 \%$ aqueous solution of fructose with the addition of cholesterol to the food and intraperitoneal administration of Poloxamer 407 to mice, respectively. The subpopulation composition of mice spleen cells was assessed by flow cytometry. Determination of leptin, adiponectin, insulin, cytokines interleukin(IL)-15, IL-22 in the blood serum of mice was performed by ELISA using commercial kits. The proliferation of lymphocytes was evaluated in the blast-transformation assay (RBTL).

Results. The results of the experiments carried out in the MS and HL models indicate a change in the population composition of the spleen (a decrease in CD4 $4^{+}$and $\mathrm{CD} 8^{+}-\mathrm{T}$ cells numbers, activation of $\mathrm{CD} 4^{+} \mathrm{CD} 25^{+} \mathrm{Foxp} 3^{+}$-Treg cells), accompanied by a decrease in the functional activity of immunocompetent $\mathrm{T}$ cells and an increase in the proliferative activity of B-lymphocytes. Also a violation of the production of IL-15 and IL-22, involved in lipid metabolism and dysfunctional changes in the mediators of lipid and carbohydrate metabolism (adiponectin, leptin, insulin) was observed, which in turn may serve as a prerequisite for the development of chronic inflammation, considered as the most important pathogenetic sign of MS.

Conclusion. Our experimental data on changes in the immune response and the state of metabolism confirm the feasibility of searching and screening for immunocorrection drugs intended for the prevention and treatment of hyperlipidemia and the MS symptom complex, based on a targeted effect on the leading steps in the pathogenesis of metabolic disease.

Keywords: metabolic syndrome; hyperlipidemia; adiponectin; leptin; experimental model; immune response; Treg cells; cytokines

Received 07.04.2021. Accepted 16.06.2021.

For citation: Nikolaeva T.N., Kozlov V.V., Kozhevnikova T.N., Grigorieva E.A., Sosnovskaya O.Yu., Cheknev S.B., Sanin A.V., Pronin A.V. Study of the immune response and metabolism state using experimental models of hyperlipidemia and metabolic syndrome. Immunologiya. 2021; 43 (4): 337-45. DOI: https://doi.org/10.33029/0206-4952-202142-4-337-345 (in Russian)

Funding. The study had no sponsor support.

Conflict of interests. The authors declare no conflict of interests.
For correspondence Tatiana N. Kozhevnikova $\mathrm{PhD}$, Researcher, Cellular Immunity Laboratory of National Research Centre for Epidemiology and Microbiology named after the honorary academician N.F. Gamaleya of the Ministry of Health of the Russian Federation, Moscow, Russian Federation E-mail: tatiana140663@gmail.com https://orcid.org/0000-0003-0507-1935 


\section{Введение}

Нарушения иммунных функций играют важную роль в патогенезе гиперлипидемии (ГЛ) и метаболического синдрома (МС). Метаболические дисфункции сопровождаются изменениями кооперации, межклеточных взаимодействий в различных звеньях иммунной системы, клеточного и гуморального иммунного ответа, активации и координации врожденного и адаптивного иммунитета [1-3].

Изменения жирового и углеводного обмена ведут к системному хроническому воспалению и метаболическим нарушениям, ассоциируются с изменениями архитектуры лимфоидной ткани, популяционного состава лимфоцитов, их фенотипа, сопровождаются изменениями активации клеток в иммунном ответе против патогенов, обусловливают аккумуляцию липидов в нежировой ткани, в том числе в иммунокомпетентных органах, включая костный мозг, тимус, лимфатические узлы [4-7].

Ассоциированная с кишечной стенкой лимфоидная ткань является связующим звеном между интестинальной микрофлорой и жировой тканью, участвует в процессинге, презентации антигенов и широко представлена различными популяциями лимфоцитов - $\mathrm{CD}^{+}$, $\mathrm{CD}^{+}, \mathrm{CD}^{+}$. Дисбиоз, изменяя метаболизм микробиома и, следовательно, метаболизм организма хозяина, влияет на воспалительные реакции и адаптивный иммунитет, а также способствует развитию метаболических нарушений [8-10].

Хорошо известна связь иммунных и метаболических процессов. У больных МС отмечена зависимость реакций клеточного иммунитета от степени дислипидемии и диспротеинемии. Отмечены высокий уровень провоспалительных $\mathrm{CD}^{+}-\mathrm{Th} 1-$-клеток и снижение противовоспалительных $\mathrm{CD}^{+}$-Treg-клеток, которые обеспечивают продукцию регуляторных цитокинов ТФР $\beta$ и интерлейкина(ИЛ)-10 [11, 12]. Обнаружено нарастание количества Th2-клеток и провоспалительных цитокинов у мышей с ожирением $[2,13,14]$. Это, в свою очередь, отражается на состоянии иммунного гомеостаза, в частности клеточного иммунного ответа.

Ключевым патогенетическим фактором ГЛ и МС, обусловливающим развитие хронического воспаления, служит изменение секреции медиаторов адипоцитов (адипонектина, лептина) и провоспалительных цитокинов, обладающих антигиперлипидемической активностью. Провоспалительные цитокины блокируют продукцию противовоспалительных и чувствительных к инсулину адипокинов, таких как адипонектин, усиливают ГЛ, гипергликемию и резистентность к инсулину $[7,15]$.

Продуцируемый адипоцитами лептин усиливает окисление жирных кислот. Его высокий уровень в циркуляции свидетельствует о нарастании резистентности к инсулину, играет регуляторную роль в отношении гемопоэза в костном мозге, влияет на генерацию Т-клеток, развитие в тимусе и детерминирование клонов Т-клеток в лимфоузлах. Дефицит лептина ассоциирован со сни- жением гемопоэза и образования Т-клеток [16]. Резистентность к инсулину, в свою очередь, связана с подавлением Т-клеточного ответа в условиях воспаления. Инсулин усиливает дифференцировку противовоспалительных Тh2-клеток [17].

Снижение чувствительности к инсулину вызывает снижение липолиза и приводит к накоплению липидов. Дисрегуляция метаболизма липидов и иммунного ответа увеличивает риск развития широкого спектра воспалительных заболеваний [7]. Активность инсулина также может быть снижена при измененной секреции цитокинов и хемокинов. У пациентов с диабетом 2-го типа циркулирующие Т-клетки продуцируют более высокие уровни ИЛ-17 и фактора некроза опухоли $\alpha$ $(\Phi Н О \alpha)$, что приводит к индукции провоспалительных эффектов в организме [7, 11, 13, 18].

Адипонектин участвует в инициации иммунного ответа. Показано, что у адипонектин-дефицитных мышей риск развития сепсиса намного выше, к тому же у них повышены частота воспалительных процессов и активность эндотелия [19].

Таким образом, накопленные данные экспериментальных и клинических исследований свидетельствуют о взаимосвязи и взаимообусловленности клеточных иммунных реакций, медиаторов межклеточных взаимодействий и мессенджеров метаболических процессов в макроорганизме.

Цель настоящего исследования - изучение популяционного состава лимфоидных клеток селезенки, продукции цитокинов и функциональной активности лимфоцитов при экспериментальном моделировании МС и ГЛ.

\section{Материал и методы}

Экспериментальные животные. Эксперименты выполнены на мышах C57Bl/6, самцах, массой 18-20 г, полученных из Центрального питомника лабораторных животных «Андреевка». Животных содержали при свободном доступе к воде и корму. Основные правила содержания и ухода соответствовали нормативным документам. Все процедуры по рутинному уходу за животными выполнялись в соответствии с приказом № 199н от 01.04.2016 Минздрава России «Об утверждении Правил лабораторной практики». Исследования проведены на моделях МС и ГЛ у экспериментальных животных.

Модель МС основана на длительном, в течение 10 нед, выпаивании животных $20 \%$ водным раствором фруктозы с добавлением в корм холестерина (0,5 \% на 100 г сухого корма) [20].

Модель ГЛ. Мышам опытной группы внутрибрюшинно вводили Полоксамер 407 (Pol 407) (Sigma, США) 2 раза в неделю в разовой дозе 500 мг/кг в течение 10 нед [21].

Контрольная группа мышей получала стандартный полусинтетический корм и воду в режиме ad libitum.

Лабораторные исследования. Суспензию клеток селезенки готовили в питательной среде RPMI 1640 
(ПанЭко, Россия), дополненной 10 \% эмбриональной телячьей сыворотки (Gibco, Thermo Scientific, США, 2 мМ глютамина (ПанЭко, Россия), 10 мМ буфера HEPES (ПанЭко, Россия), 40 мкг/мл гентамицина (ПанЭко, Россия). Клетки отмывали (800 об/мин, 10 мин при $\left.4{ }^{\circ} \mathrm{C}\right)$. Подсчет жизнеспособных клеток проводили в растворе трипанового синего.

Для оценки субпопуляционного состава клетки селезенки мышей метили конъюгатом моноклональных антител с флуоресцентными красителями Anti-Mouse CD19-PE (BD Biosciences, США), и Anti-Mouse CD4APC, CD8-PE (eBioscience, CША). Анализ клеток проводили на проточном цитофлуориметре «FACSCanto II» (BD Biosciences, США). Обработку данных осуществляли в программе FACSDiva 6.1.3 (BD Biosciences, США). Кратко: на дот-плоте прямого и бокового светорассеяния выделяли популяцию лимфоцитов. Далее на гистограмме популяции лимфоцитов выделяли клетки, меченые по CD4, CD8, CD19. Рассчитывали средние значения количества клеток селезенки в группе.

Для оценки экспрессии транскрипционного фактора Foxp3 клетки селезенки мышей метили конъюгатом моноклональных антител с флуоресцентными красителями Anti-Mouse CD4-FITC, Anti-Mouse CD25-APC и Anti-Mouse Foxp3-PE в соответствии с инструкцией производителя (eBioscience Mouse Regulatory T Cell Staining Kit). Анализ клеток проводили на проточном цитофлуориметре «FACSCanto II» (BD Biosciences, США). Обработку данных осуществляли в программе FACSDiva 6.1.3 (BD Biosciences, СШA). Рассчитывали средние значения экспрессии CD25 и транскрипционного фактора Foxp3 в CD4-T-клетках селезенки мышей в группе.

Содержание липопротеинов высокой (ЛПВП) и низкой плотности (ЛПНП), общего холестерина, триглицеридов, глюкозы в плазме крови определяли на биохимическом анализаторе «Beckman Coulter 680» (Beckman Coulter, США). Для определения лептина и адипонектина в сыворотке крови мышей использовали коммерческие наборы фирмы AssayPro, инсулина - фирмы RayBiotech (США), измерения проводили методом ELISA на спектофотометре «Multiskan FC Termo Fisher» (Termo Fisher Scientific, США) с использованием программы SkanItSoftware 3.0 (Termo Fisher Scientific, США). Про- дукцию цитокинов ИЛ-15 и ИЛ-22 в сыворотке крови контрольных и опытных групп мышей определяли иммуноферментным методом (ELISA) с использованием коммерческих наборов «R\&D Systems» (США).

Пролиферацию лимфоцитов оценивали в реакции бласттрансформации в присутствии Т-митогена конканавалина А (КонА) (Sigma, США) в конечной концентрации 4,0 мкг/мл или В-митогена липополисахарида (ЛПС) (Sigma, США) в дозе 200 мкг/мл по включению ${ }^{3}$ Н-тимидина с удельной активностью 1 Ки/мМ (Изотоп, Россия) в ДНК клеток контрольных и опытных групп животных. Подсчет радиоактивности осуществляли на сцинтилляционном счетчике «MicroBeta2» (PerkinElmer, США) в течение 1 мин.

Каждая группа животных включала по 5-10 мышей. Эксперименты выполнены в четырех повторах.

Статистическая обработка. При математической обработке результатов $(M \pm m)$ достоверность различия средних величин устанавливали с помощью $t$-критерия Стьюдента $(p \leq 0,05)$.

\section{Результаты}

Исследования, проведенные спустя 10 нед после начала эксперимента, показали, что в результате выпаивания мышей 20 \% раствором фруктозы с добавлением в корм холестерина (модель 1) или введения Pol 407 (модель 2) относительная масса печени животных увеличивалась по сравнению с таковой в контрольной группе мышей $(p \leq 0,05)$ (табл. 1$)$.

Результаты проведенных биохимических исследований свидетельствуют о выраженной дислипидемии и гипергликемии в опытных группах животных. Полученные данные обнаруживают более глубокие нарушения липидного обмена при внутрибрюшинном введении мышам Pol 407 - об этом свидетельствует высокие уровни холестерина, триглицеридов, ЛПНП ( $p \leq 0,05)$. У мышей, получавших фруктозу в комплексе с холестерином, в отличие от мышей группы с Pol 407, наблюдается существенный рост уровня глюкозы в сыворотке крови $(p \leq 0,05)$ (см. табл. 1$)$.

Анализ экспрессии поверхностных антигенов на лимфоцитах селезенки показывает, что в группе мышей с внутрибрюшинным введением Pol 407 (модель ГЛ), наблюдается значительное снижение численности

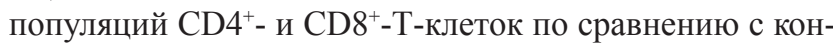

Таблица 1. Показатели липидного и углеводного обмена в сыворотке крови мышей, масса печени мышей $(M \pm m)$

\begin{tabular}{|l|c|c|c|c|}
\hline \multirow{2}{*}{ Показатель } & Единица измерения & \multicolumn{3}{|c|}{ Группа животных } \\
\cline { 3 - 5 } & & контроль & $\mathbf{2 0} \%$ фруктоза + холестерин & Pol 407 \\
\hline Масса печени & Г & $0,73 \pm 0,07$ & $1,37 \pm 0,01 \uparrow \uparrow *$ & $1,59 \pm 0,06 \uparrow \uparrow *$ \\
\hline Холестерин & ммоль/л & $2,69 \pm 0,14$ & $2,41 \pm 0,12$ & $19,66 \pm 0,69 \uparrow \uparrow * / * *$ \\
\hline Триглицериды & ммоль/л & $1,34 \pm 0,09$ & $0,61 \pm 0,07 \downarrow \downarrow *$ & $2,46 \pm 0,17 \uparrow \uparrow * / * *$ \\
\hline ЛПВП & ммоль/л & $1,63 \pm 0,08$ & $1,63 \pm 0,03$ & $1,99 \pm 0,03 \uparrow \uparrow * / * *$ \\
\hline ЛПНП & ммоль/л & $0,65 \pm 0,04$ & $0,52 \pm 0,07$ & $3,14 \pm 0,11 \uparrow \uparrow * *$ \\
\hline Глюкоза & ммоль/л & $2,72 \pm 0,08$ & $6,71 \pm 0,16 \uparrow \uparrow * / * *$ & . \\
\hline
\end{tabular}

Примечание. Здесь, во всех таблицах и на рисунках: * - достоверные различия по сравнению с контролем; ** - достоверные различия между группами ( $p \leq 0,05)$. 


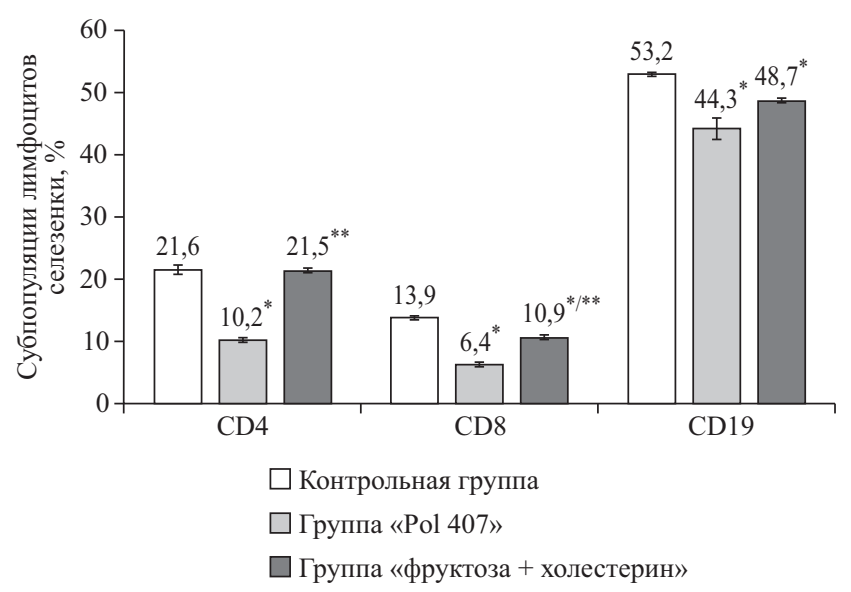

Рис. 1. Субпопуляционный состав клеток селезенки мышей $(M \pm m)$

трольной группой животных (рис. $1 ; p<0,05)$. При этом соотношение CD4/CD8 соответствует показателям контрольной группы. Общее количество В-клеток $\left(\mathrm{CD} 19^{+}\right)$ снижено по сравнению с контролем (см. рис. $1 ; p<0,05)$.

При моделировании МС с использованием длительного выпаивания животных 20 \% водным раствором фруктозы и добавления в корм холестерина отмечено

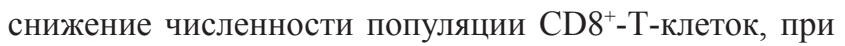
этом численность популяции $\mathrm{CD}^{+}$-Т-клеток и общее количество Т-клеток не изменились по сравнению с показателями контрольной группы (см. рис. 1; $p<0,05)$. Соотношение CD4/CD8 в данной группе повышено по сравнению с контролем. Общее количество B-клеток $\left(\mathrm{CD} 19^{+}\right)$снижено в меньшей степени, чем в группе животных с ГЛ (см. рис. $1, p<0,05)$.

Анализ экспрессии маркеров Т-регуляторных клеток свидетельствует, что количество CD4+-Т-клеток, экспрессирующих CD25, Foxp3 и CD25 $5^{+}$oxp3 $3^{+}$, в группе животных с введением Pol 407 (модель ГЛ) повышено по сравнению с контрольной группой (рис. $2 ; p<0,05$ ).

Моделирование МС с использованием длительного выпаивания животных водным раствором фруктозы с добавлением в корм холестерина не выявило, в отличие от животных в группе с ГЛ, увеличения количества $\mathrm{CD} 4^{+}-$ T-клеток, экспрессирующих маркер CD25, и CD25+-Tклеток, экспрессирующих Foxp3 (CD25+Foxp $3^{+}$), показатели активации которых ниже значений в группе животных с ГЛ и не отличаются от таковых в контроле (см. рис. 2). При этом количество $\mathrm{CD}^{+} \mathrm{Foxp}^{+}-$ Т-клеток превышает аналогичные показатели контроля (см. рис. 2). Treg-клетки $\left(\mathrm{CD} 4^{+} \mathrm{CD} 25^{+} \mathrm{Foxp}^{+}\right)$контроли-



Рис. 2. Уровень CD25 и транскрипционного фактора Foxp3 в CD4+-T-клетках селезенки мышей $(M \pm m)$

руют функциональную активность иммунокомпетентных Th1-, Th2- и Th17-клеток в ходе развития иммунного ответа на патогены.

Функциональная активность спленоцитов спустя 10 нед от начала эксперимента снижается в обеих экспериментальных группах в присутствии Т-митогена КонА, в большей степени - при введении Pol 407, на модели ГЛ $(p \leq 0,05)$. Присутствие в среде культивирования спленоцитов В-митогена ЛПС, напротив, усиливает пролиферативную активность В-лимфоцитов, показатели которой оказываются выше в группе с выпаиванием мышей раствором фруктозы и добавлением в корм холестерина, модель МС (табл. 2).

Включение ${ }^{3} \mathrm{H}$-тимидина клетками селезенки в среде без митогенов (спонтанная пролиферация) имеет тенденцию к снижению по сравнению с контролем в группах животных с МС и ГЛ в 1,68 и 2,37 раза соответственно ( $p \leq 0,05$; см. табл. 2).

Обнаруженные изменения популяционного состава и функциональной активности лимфоцитов селезенки наблюдаются на фоне нарушений жирового и углеводного обмена у мышей при моделировании ГЛ и МС об этом свидетельствуют результаты определения медиаторов адипоцитов (адипонектина, лептина), инсулина и цитокинов ИЛ-15, ИЛ-22, вовлеченных в метаболические процессы (табл. 3).

Выявлены различия в содержании лептина, адипонектина и инсулина в сыворотке крови мышей опытных групп по сравнению с контролем (см. табл. 3). Показано, что уровень адипонектина в сыворотке повышен в группе с внутрибрюшинным введением Pol 407 (модель ГЛ). В большей степени снижение содержания лептина

Таблица 2. Пролиферация спленоцитов в присутствии Т- и В-митогенов (имп/мин $\left.\cdot 10^{-3}\right)(M \pm m)$

\begin{tabular}{|l|c|c|c|}
\hline \multicolumn{1}{|c|}{ Группа } & Без митогена & КонА & ЛПС \\
\hline Контроль & $6,277 \pm 0,944$ & $109,969 \pm 7,007$ & $28,735 \pm 2,765$ \\
\hline Фруктоза + холестерин & $4,439 \pm 0,472 \downarrow \downarrow^{*}$ & $89,721 \pm 4,688 \downarrow \downarrow *$ & $48,336 \pm 3,088 \uparrow \uparrow *$ \\
\hline Pol 407 & $4,465 \pm 0,371 \downarrow \downarrow^{*}$ & $73,703 \pm 3,563 \downarrow \downarrow * / *$ & $35,377 \pm 2,257 \uparrow \uparrow * / * *$ \\
\hline
\end{tabular}

Примечание. КонА - конканавалин А; ЛПС-липополисахарид. 
и высокий уровень инсулина отмечены в сыворотке крови мышей, получавших фруктозу в комплексе с холестерином (модель МС), по сравнению с группой мышей, которым вводили Pol 407 (модель ГЛ), и контрольной группой, соответственно.

\section{Обсуждение}

Результаты проведенных исследований на экспериментальных моделях ГЛ и МС показали изменения клеточного иммунного ответа и дисфункцию метаболизма. Полученные данные свидетельствуют об изменении популяционного клеточного состава спленоцитов, снижении численности $\mathrm{CD}^{+}$- и $\mathrm{CD} 8^{+}$-Т-клеток, активации популяции Treg, снижении численности В-клеток (CD19 $\left.{ }^{+}\right)$ у мышей опытных групп по сравнению с аналогичными показателями в контроле. Более существенные пертурбации популяционного состава спленоцитов по сравнению с контролем выявлены при ГЛ.

При этом функциональная активность Т-лимфоцитов снижается в обеих экспериментальных группах, в большей степени - на модели ГЛ. Напротив, наблюдается усиление пролиферативной активности В-лимфоцитов, показатели которой выше в группе, где моделировали МC (с выпаиванием мышей раствором фруктозы и добавлением в корм холестерина).

В развитии иммунного ответа связующим звеном между иммунной и другими системами макроорганизма выступают цитокины. Оценка уровня цитокинов, вовлекаемых в липидный обмен и продуцируемых макрофагами и адипоцитами, свидетельствует о более высоком содержании ИЛ-15 и ИЛ-22 в группе мышей с моделью МC. Напротив, в группе с моделью ГЛ отмечено снижение ИЛ-22 по сравнению с показателями контрольной группы и группы животных с моделью МС (см. табл. 3).

ИЛ-15 служит фактором роста для активированных Т-, В-, НК- и НКТ-клеток. Рецепторы ИЛ-15 экспрессируются Т- и НК-клетками, моноцитами, клетками эпителия [22, 23].

ИЛ-22 является членом семейства ИЛ-10, которое предотвращает или корректирует индуцированную в условиях ожирения непереносимость глюкозы и резистентность к инсулину. ИЛ-22 также обеспечивает поддержание целостности эпителиального барьера слизистой оболочки кишечника, тормозит развитие эндотоксемии и хронического воспаления. Содержание ИЛ-22 в сыворотке крови пациентов с МС значимо ниже, чем в контроле. Уровень сывороточного ИЛ-22 отрицательно коррелирует со степенью ожирения, уровнем
C-реактивного белка и триглицеридов и положительно с количеством холестерина и ЛПВП. Логистический регрессионный анализ подтверждает, что снижение уровня ИЛ-22 может служить биомаркером МС [24-27]. Данные о снижении уровня ИЛ-22, полученные нами на модели с использованием Pol 407 (модель ГЛ), подтверждают это положение и могут быть применимы в дальнейшем для оценки эффективности лекарственных препаратов, разрабатываемых в целях профилактики и лечения МС.

Выявленные изменения популяционного состава и функциональной активности лимфоцитов селезенки наблюдаются на фоне нарушений липидного и углеводного обмена у мышей при моделировании ГЛ и МС об этом говорят результаты определения медиаторов адипоцитов (адипонектина, лептина), инсулина соответственно,

Результаты проведенных исследований свидетельствуют о более высоком уровне адипонектина в сыворотке крови в группе с внутрибрюшинным введением Pol 407 (модель ГЛ). При этом в большей степени наблюдается снижение содержания лептина и высокий уровень инсулина в сыворотке крови мышей, получавших фруктозу в комплексе с холестерином (модель МС), по сравнению с ранее описанной группой и контролем соответственно (см. табл. 3).

Одним из ведущих факторов развития МС выступает резистентность к инсулину. Гипертрофия жировой ткани сопровождается снижением выработки противовоспалительного адипонектина и ростом продукции провоспалительных ФНО $\alpha$, ИЛ-6, лептина, резистина, которые снижают чувствительность тканей к инсулину. Наиболее специфичный гормон жировой ткани - лептин. Проникая через гематоэнцефалический барьер, он вызывает снижение аппетита, оказывает стимулирующее действие на симпатическую нервную систему, в периферических тканях участвует в активации $\beta$-окисления свободных жирных кислот, предотвращая реализацию липотоксичности. Кроме того, лептин снижает синтез и секрецию инсулина. У пациентов с ожирением и МС развивается ГЛ с последующей селективной лептинорезистентностью, приводящей к снижению анорексигенного действия лептина и преобладанию липогенеза над липолизом [11, 17, 28, 29].

Развитие МС сопровождается также повышением уровня инсулина с одновременным повышением резистентности к нему и снижением уровня адипонектина гормона, содержание которого обратно связано с индек-

Таблица 3. Содержание медиаторов липидного, углеводного обмена и цитокинов в сыворотке крови мышей $(M \pm m)$

\begin{tabular}{|l|c|c|c|}
\hline \multicolumn{1}{|c|}{ Показатель } & \multicolumn{3}{|c|}{ Группа животных } \\
\cline { 2 - 4 } & контроль & фруктоза + холестерин & Роl 407 \\
\hline Адипонектин, нг/мл & $10096,18 \pm 245,17$ & $9580,05 \pm 450,10$ & $3751,17 \pm 31,16 \uparrow \uparrow *$ \\
\hline Лептин, нг/мл & $5,41 \pm 1,14$ & $2,39 \pm 0,09 \downarrow \downarrow *$ & $2,63 \pm 0,02 \downarrow \downarrow * *$ \\
\hline Инсулин, Ед/мл & $2,86 \pm 0,97$ & $14,77 \pm 2,08 \uparrow \uparrow *$ & $8,57 \pm 0,13 \uparrow \uparrow^{*}$ \\
\hline ИЛ-15, пг/мЛ & $6,97 \pm 0,24$ & $10,20 \pm 0,96 \uparrow \uparrow *$ & $15,51 \pm 1,3 \downarrow \downarrow * / *$ \\
\hline ИЛ-22, пг/мл & $26,9 \pm 2,9$ & $57,9 \pm 3,17 \uparrow \uparrow *$ & $*$ \\
\hline
\end{tabular}


сом атерогенности и степенью ожирения [30]. У мышей с дислипидемией уровень адипонектина был снижен на фоне повышенного уровня инсулина в сыворотке крови.

Диагностическими признаками нарушения липидного обмена являются высокий уровень холестерина, триглицеридов, ЛПНП при внутрибрюшинном введении мышам Pol 407. У мышей, получавших фруктозу в комплексе с холестерином, в отличие от животных группы с Pol 407, отмечен существенный рост уровня глюкозы в сыворотке крови, свидетельствующий о нарушении углеводного обмена.

Полученные результаты согласуются с данными клинических исследований, свидетельствующими, что на первой стадии развития МС возникает диспротеинемия (снижение ЛПВП и повышение ЛПНП), в иммунный ответ вовлекаются зрелые Т- и В-клетки $\left(\mathrm{CD}^{+}, \mathrm{CD} 19^{+}\right)$, $\mathrm{CD}^{+} \mathrm{CD}^{+}$-T-хелперы, $\mathrm{CD} 3^{+} \mathrm{CD} 19^{-}$-Т-клетки, цитоток-

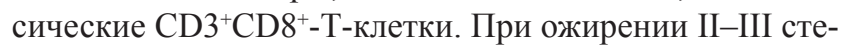
пени с очевидным развитием ГЛ наблюдают увеличение количества цитотоксических Т-лимфоцитов, $\mathrm{CD}^{+}{ }^{+} \mathrm{CD} 16^{-} \mathrm{CD} 56^{+}$-НКT-клеток, $\mathrm{CD} 3{ }^{-} \mathrm{CD} 16^{+} \mathrm{CD} 56^{+}$-HКклеток, повышение уровня провоспалительных цитокинов ИЛ-6 и ФНО $\alpha[12,13,31]$.

Таким образом, результаты проведенных исследований в условиях моделирования ГЛ и МС свидетельствуют об изменении популяционного состава клеток селезенки (снижение численности $\mathrm{CD}^{+}-$и $\mathrm{CD}^{+}-\mathrm{T}-$ клеток, активация $\mathrm{CD} 4^{+} \mathrm{CD} 25^{+} \mathrm{Foxp} 3^{+}$-Treg-клеток), которое сопровождается снижением функциональной активности Т-клеток и нарастанием пролиферативной активности В-лимфоцитов, а также нарушением продукции ИЛ-15 и ИЛ-22, вовлекаемых в липидный обмен, и изменением выработки медиаторов липидного и углеводного обмена. Указанные изменения, в свою очередь, служат предпосылкой развития хронического воспаления, выступающего одним из основных патогенетических проявлений метаболической болезни.

\section{Заключение}

Полученные данные по изменению иммунного ответа и состояния метаболизма подтверждают целесообразность поиска и скрининга иммунокорригирующих лекарственных средств, предназначенных для профилактики и лечения гиперлипидемии и симптомокомплекса МС, исходя из целенаправленного воздействия на ведущие звенья патогенеза метаболической болезни.

Вклад авторов. Сбор и обработка материала - Николаева Т.Н., Козлов В.В., Кожевникова Т.Н., Сосновская О.Ю., Григорьева Е.А.; написание текста - Николаева Т.Н., Козлов В.В., Кожевникова Т.Н.; статистическая обработка - Николаева Т.Н., Козлов В.В.; разработка схемы эксперимента и обсуждение результатов - Чекнёв С.Б., Санин А.В., Пронин А.В.

\section{- Литература}

1. Andersen C.J., Murphy K.E., Fernandez M.L. Impact of obesity and metabolic syndrome on immunity. Adv. Nutr. 2016; 7 (1): 66-75. DOI: https://doi.org/10.3945/an.115.010207

2. Feuerer M., Herreto L., Cipolletta D., NaazA., Wong J., Nayer A., Lee J., Goldfine A.B., Benoist C., Shoelson S. Lean, but not obese, fat is enriched for a unique population of regulatory $\mathrm{T}$ cells that affect metabolic parameters. Nat. Med. 2009; 15: 930-9. DOI: https://doi. org/10.1038/nm.2002

3.Rius B.,Lopez-Vicario C., Gonzalez-PerizA., Moran-SalvadorE., Garcia-Alonso V., Claria J., Titos E. Resolusion of inflammation in obesity-induced liver disease. Front. Immunol. 2012; 3: 257. DOI: https://doi.org/10.3389/fimmu.2012.00257

4. Karlsson E.A., Sheridan P.A, Beck M.A. Diet-induced obesity in mice reduces the maintenance of influenza-specific $\mathrm{CD}^{+}$memory $\mathrm{T}$ cells J. Nutr. 2010; 140: 1691-7. DOI: https://doi.org/10.3945/ jn. 110.123653

5. Kanneganti T.D., Dixit V.D. Immunological complication of obesity. Nat. Immunol. 2012; 13: 707-12. DOI: https://doi.org/ 10.1038/ni.2343

6. Yang H., Youm Y.H., Vandanmagsar B., Ravussin A., Gimble J.M., Greenway F., Stephens J.M., Mynatt R.L, Dixit V.D. Obesity increases the production of proinflammatory mediators from adipose tissue $\mathrm{T}$ cell and compromises TCR receptoire diversity implications for systemic inflammation and insulin resistance. J. Immunol. 2010; 185: 1836-45. DOI: https://doi.org/10.4049/jimmunol. 1000021

7. Guilherme A., Virbasius J.V.. Puri V., Czech M.P. Adipocyte dysfunctions linking obesity to insulin resistance and type 2 diabetes. Nat. Rev. Mol. Cell Biol. 2008; 9: 231-7. DOI: https://doi.org/10.1038/ nrm2391

8. Belizário J.E., Faintuch J., Garay-Malpartida M. Gut microbiome dysbiosis and immunometabolism: new frontiers for treatment of metabolic diseases. Mediators Inflamm. 2018; 2018: 2037838. DOI: https://doi.org/10.1155/2018/2037838

9. Плотникова Е.Ю., Краснов О.А. Метаболический синдром и кишечная микробиота: что общего? Экспериментальная и клиническая гастроэнтерология. 2014; 112 (12): 64-73.
10. Зверев В.В., Максимова О.В., Гервазиева В.Б. Микробиота кишечника и ее связь с ожирением. Инфекционные болезни. 2014 ; 12 (3): 69-79.

11. O’ Rourke R.W., Kay T., Scholz M.H., Diggs B., Jobe B.A., Lewinsohn D.M., Bakke A.C. Alteration in T-cell subset frequency in peripheral blood in obesity. Obes. Surg. 2005; 15: 1463-8. DOI: https://doi.org/10.1381/096089205774859308

12. Салихова А.Ф., Фархутдинова Л.М. Роль цитокинов в патогенезе ожирения. Цитокины и воспаление. 2013; 12 (3): 21-4.

13. Van der Weerd K., Dik W.A., Schrijver B., Schweitzer D.H., Langerak A.W., Drexhage H.A., Kiewiet R.M. et al. Morbidly obese human subjects have increased peripheral blood $\mathrm{CD}^{+} \mathrm{T}$ cells with skewing toward a Treg and Th2-dominated phenotype. Diabetes. 2012; 61: 401-8. DOI: https://doi.org/10.2337/db11-1065

14. Issazadeh-Navikas S., Teimer R., Bockermann R. Influence of dietary components on regulatory T cells. Mol. Med. 2012; 18: 95 110. DOI: https://doi.org/10.2119/molmed.2011.00311

15. Huand P.L. A comprehensive definition for metabolic syndrome. Dis. Model. Mech. 2009; 2: 231-7. DOI: https://doi. org/10.1242/dmm.001180

16. Maciver N.J., Jacobs S.R., Wieman H.L., Wofford J.A., Coloff J.L., Rathmell J.C. Glucose metabolism in lymphocytes is a regulated process with significant effects on immune cell function and survival. J. Leukoc. Biol. 2008; 84: 949-57. DOI: https://doi. org/10.1189/jlb.0108024

17. Viardot A., Grey S.T., Mackay F., Chisholm D. Potential anti-inflammatory role of insulin via the preferential polarization of effector T cells toward a T helper 2 phenotype. Endocrinology. 2007; 148: 346-53. DOI: https://doi.org/10.1210/en.2006-0686

18. Jagannathan-Bogdan M., McDonnell M.E., Shin H., Rehman Q. et al. Elevated proinflammatory cytokine production by a skewed $\mathrm{T}$ cell compartment requires monocytes and promotes inflammation in type 2 diabetes. J. Immunol. 2011; 186: 1162-72. DOI: https://doi. org/10.4049/jimmunol.1002615

19. Teoh H., Quan A., Bang G., Wang G., Lovren F., Vu V., Haitsma J.J., Szmitko P.E., Al-Omran M., Wang C.H. Adiponectin deficiency promotes endothelial activation and promofoundly exac- 
erbates sepsis-related mortality. Am. J. Physiol. Endocrinol. Metab. 2008; 295: E658-64. DOI: https://doi.org/10.1152/ajpendo.90384. 2008

20. Макарова М.Н., Макаров В.Г. Диет-индуцированные модели метаболических нарушений, экспериментальный метаболический синдром. Лабораторные животные для научных исследований. 2018; 1: 79-91

21. Johnston T.P. The P-407-induced murine model of dose-controlled hyperlipidemia and atherosclerosis: a review of findings to date. J. Cardiovasc. Pharmacol. 2004; 43 (4): 595-606. DOI: https:// doi.org/10.1097/00005344-200404000-00016

22. Lacraz G., Rakotoarivelo V., Labbé S.M., Vernier M., Noll C., Mayhue M., Stankova J., Schwertani A., Grenier G., Carpentier A., Richard D., Ferbeyre G., Fradette J., Rola-Pleszczynski M., Menendez A., Langlois M.F., Ilangumaran S., Ramanathan S. Deficiency of Interleukin-15 confers resistance to obesity by diminishing inflammation and enhancing the thermogenic function of adipose tissues. PLoS One. 2016; 11 (9): e0162995. DOI: https://doi.org/10.1371/journal pone. 0162995

23. Barra N.G. et al. Interleukin-15 contributes to the regulation of murine adipose tissue and human adipocytes. Obesity (Silver Spring). 2010; 18 (8): 1601-7. DOI: https://doi.org/10.1038/oby. 2009.445

24. Yilmaz H. Decreased circulating levels of IL-22 in newly diagnosed metabolic syndrome patients. J. Clin. Anal. Med. 2018; 9 (4) $310-4$.
25. Dudakov J.A. Interleukin-22: immunobiology and pathology Annu. Rev. Immunol. 2015; 33: 747-85. DOI: https://doi.org/10.1146/ annurev-immunol-032414-112123

26. Park O. et al. Biologically active, high levels of interleukin-22 inhibit hepatic gluconeogenesis but do not affect obesity and its metabolic consequences. Cell Biosci. 2015; 5: 25. DOI: https://doi. org/10.1186/s13578-015-0015-0

27. Zenewicz L.A. IL-22: there is a gap in our knowledge. Immuno Horizons. 2018; 2 (6): 198-207. DOI: https://doi.org/10.4049/ immunohorizons. 1800006

28. Салихова А.Ф., Фархутдинова Л.М. Иммунологические особенности при ожирении и их взаимосвязь с нарушениями углеводного обмена. Медицинская иммунология. 2013; 15 (5): 465-70.

29. Ballak D.B., Stienstra R. et al. IL-1 family members in the pathogenesis and treatment of metabolic disease: focus on adipose tissue inflammation and insulin resistance. Cytokine. 2015; 75 (2) 280-90. DOI: https://doi.org/1016/j.cyto.2015.05.005

30. Silvia de Barros-Mazon S., Marin D.M., de Carvalho C.P. Alegre S.M. Inflammatory and metabolic markers in pre- and posttreatment of obesity. Antiobes. Drug Discov. Dev. 2011; 1: 49-66. DOI: https://doi.org/10.2174/978160805163211101010049

31. Перминова О.М., Вольский Н.Н., Кудаева О.Т., Гойман Е.В., Козлов В.А. Дислипидемия и Th1/Th2-соотношение на разных этапах развития хронической реакции «трансплантат против хозяина. Иммунология. 2009; 30 (6): 341-5.

\section{- References}

1. Andersen C.J., Murphy K.E., Fernandez M.L. Impact of obesity and metabolic syndrome on immunity. Adv. Nutr. 2016; 7 (1): 66-75. DOI: https://doi.org/10.3945/an.115.010207

2. Feuerer M., Herreto L., Cipolletta D., NaazA., Wong J., Nayer A., Lee J., Goldfine A.B., Benoist C., Shoelson S. Lean, but not obese, fat is enriched for a unique population of regulatory T cells that affect metabolic parameters. Nat. Med. 2009; 15: 930-9. DOI: https://doi. org/10.1038/nm.2002

3. Rius B.,Lopez-Vicario C. Gonzalez-PerizA.,Moran-SalvadorE., Garcia-Alonso V., Claria J., Titos E. Resolusion of inflammation in obesity-induced liver disease. Front. Immunol. 2012; 3: 257. DOI https://doi.org/10.3389/fimmu.2012.00257

4. Karlsson E.A., Sheridan P.A, Beck M.A. Diet-induced obesity in mice reduces the maintenance of influenza-specific $\mathrm{CD} 8^{+}$memory T cells J. Nutr. 2010; 140: 1691-7. DOI: https://doi.org/10.3945/ jn. 110.123653

5. Kanneganti T.D., Dixit V.D. Immunological complication of obesity. Nat. Immunol. 2012; 13: 707-12. DOI: https://doi. org/10.1038/ni.2343

6. Yang H., Youm Y.H., Vandanmagsar B., Ravussin A., Gimble J.M., Greenway F., Stephens J.M., Mynatt R.L, Dixit V.D. Obesity increases the production of proinflammatory mediators from adipose tissue $\mathrm{T}$ cell and compromises TCR receptoire diversity implications for systemic inflammation and insulin resistance. J. Immunol. 2010; 185: 1836-45. DOI: https://doi.org/10.4049/jimmunol 1000021

7. Guilherme A., Virbasius J.V.. Puri V., Czech M.P. Adipocyte dysfunctions linking obesity to insulin resistance and type 2 diabetes Nat. Rev. Mol. Cell Biol. 2008; 9: 231-7. DOI: https://doi.org/10.1038/ nrm2391

8. Belizário J.E., Faintuch J., Garay-Malpartida M. Gut microbiome dysbiosis and immunometabolism: new frontiers for treatment of metabolic diseases. Mediators Inflamm. 2018; 2018: 2037838. DOI: https://doi.org/10.1155/2018/2037838

9. Plotnikova E.Yu., Krasnov O.A. Metabolic syndrome and intestinal microbiota: what is common? Experimental and clinical gastroenterology. 2014; 112 (12): 64-73. (in Russian)

10. Zverev V.V., Maksimova O.V., Gervazieva V.B. Intestinal microbiota and its relationship with obesity. Infectious diseases. 2014; 12 (3): 69-79. (in Russian)

11. O’Rourke R.W., Kay T., Scholz M.H., Diggs B., Jobe B.A., Lewinsohn D.M., Bakke A.C. Alteration in T-cell subset frequency in peripheral blood in obesity. Obes. Surg. 2005; 15: 1463-8. DOI https://doi.org/10.1381/096089205774859308

12. Salikhova A.F., Farkhutdinova L.M. The role of cytokines in the pathogenesis of obesity. Cytokines and inflammation. 2013; 12 (3): 21-4. (in Russian)
13. Van der Weerd K., Dik W.A., Schrijver B., Schweitzer D.H. Langerak A.W., Drexhage H.A., Kiewiet R.M., et al. Morbidly obese human subjects have increased peripheral blood $\mathrm{CD}^{+} \mathrm{T}$ cells with skewing toward a Treg and Th2-dominated phenotype. Diabetes. 2012; 61: 401-8. DOI: https://doi.org/10.2337/db11-1065

14. Issazadeh-Navikas S., Teimer R., Bockermann R. Influence of dietary components on regulatory T cells. Mol. Med. 2012; 18: 95110. DOI: https://doi.org/10.2119/molmed.2011.00311

15. Huand P.L. A comprehensive definition for metabolic syndrome. Dis. Model. Mech. 2009; 2: 231-7. DOI: https://doi org $/ 10.1242 / \mathrm{dmm} .001180$

16.MaciverN.J.,JacobsS.R.,WiemanH.L.,WoffordJ.A.,ColoffJ.L., Rathmell J.C. Glucose metabolism in lymphocytes is a regulated process with significant effects on immune cell function and survival. J. Leukoc. Biol. 2008; 84: 949-57. DOI: https://doi.org/10.1189/ jlb.0108024

17. Viardot A., Grey S.T., Mackay F., Chisholm D. Potential antiinflammatory role of insulin via the preferential polarization of effector T cells toward a T helper 2 phenotype. Endocrinology. 2007; 148: 346-53. DOI: https://doi.org/10.1210/en.2006-0686

18. Jagannathan-Bogdan M., McDonnell M.E., Shin H., Rehman Q., et al. Elevated proinflammatory cytokine production by a skewed $\mathrm{T}$ cell compartment requires monocytes and promotes inflammation in type 2 diabetes. J. Immunol. 2011; 186: 1162-72. DOI: https://doi. org/10.4049/jimmunol.1002615

19. Teoh H., Quan A., Bang G., Wang G., Lovren F., Vu V., Haitsma J.J., Szmitko P.E., Al-Omran M., Wang C.H. Adiponectin deficiency promotes endothelial activation and promofoundly exacerbates sepsis-related mortality. Am. J. Physiol. Endocrinol. Metab. 2008; 295: E658-64. DOI: https://doi.org/10.1152/ajpendo.90384. 2008

20. Makarova M.N., Makarov V.G., Diet-induced models of metabolic disorders, experimental metabolic syndrome. Laboratory animals for scientific research. 2018; 1: 79-91. (in Russian)

21. Johnston T.P. The P-407-induced murine model of dose-controlled hyperlipidemia and atherosclerosis: a review of findings to date. J. Cardiovasc. Pharmacol. 2004; 43 (4): 595-606. DOI: https:// doi.org/10.1097/00005344-200404000-00016

22. Lacraz G., Rakotoarivelo V., Labbé S.M., Vernier M., Noll C., Mayhue M., Stankova J., Schwertani A., Grenier G., Carpentier A., Richard D., Ferbeyre G., Fradette J., Rola-Pleszczynski M., Menendez A., Langlois M.F., Ilangumaran S., Ramanathan S. Deficiency of Interleukin-15 confers resistance to obesity by diminishing inflammation and enhancing the thermogenic function of adipose tissues. PLoS One. 2016; 11 (9): e0162995. DOI: https://doi.org/10.1371/journal. pone. 0162995 
23. Barra N.G., et al. Interleukin-15 contributes to the regulation of murine adipose tissue and human adipocytes. Obesity (Silver Spring). 2010; 18 (8): 1601-7. DOI: https://doi.org/10.1038/oby.2009.445

24. Yilmaz H. Decreased circulating levels of IL-22 in newly diagnosed metabolic syndrome patients. J. Clin. Anal. Med. 2018; 9 (4): $310-4$.

25. Dudakov J.A. Interleukin-22: immunobiology and pathology. Annu. Rev. Immunol. 2015; 33: 747-85. DOI: https://doi.org/10.1146/ annurev-immunol-032414-112123

26. Park O., et al. Biologically active, high levels of interleukin-22 inhibit hepatic gluconeogenesis but do not affect obesity and its metabolic consequences. Cell Biosci. 2015; 5: 25. DOI: https://doi. org/10.1186/s13578-015-0015-0

27. Zenewicz L.A. IL-22: there is a gap in our knowledge. Immuno Horizons. 2018; 2 (6): 198-207. DOI: https://doi.org/10.4049/ immunohorizons. 1800006

\section{Сведения об авторах}

Николаева Татьяна Николаевна - д-р мед. наук, вед. науч сотр., зав. лаб. естественного иммунитета ФГБУ «НИЦЭМ им. Н.Ф. Гамалеи» Минздрава России, Москва, Российская Федерация

E-mail: tatyananik.55@mail.ru

https://orcid.org/0000-0001-6226-7251

Козлов Вячеслав Владимирович - науч. сотр. лаб. естественного иммунитета ФГБУ «НИЦЭМ им. Н.Ф. Гамалеи» Минздрава России, Москва, Российская Федерация

E-mail: hyperslava@yandex.ru

https://orcid.org/0000-0002-0502-4824

Кожевникова Татьяна Николаевна - канд. мед. наук, науч. сотр лаб. клеточного иммунитета ФГБУ «НИЦЭМ им. Н.Ф. Гамалеи» Минздрава России, Москва, Российская Федерация

E-mail: tatiana140663@gmail.com

https://orcid.org/0000-0003-0507-1935

Григорьева Екатерина Анатольевна - канд. биол. наук, науч. сотр. лаб. естественного иммунитета ФГБУ «НИЦЭМ им. Н.Ф. Гамалеи» Минздрава России, Москва, Российская Федерация E-mail: katigr@yandex.ru

https://orcid.org/0000-0001-7811-3740

Сосновская Ольга Юрьевна - канд. биол. наук, ст. науч. сотр. лаб. клеточного иммунитета, ФГБУ «НИЦЭМ им. Н.Ф. Гамалеи» Минздрава России, Москва, Российская Федерация

E-mail: sosnovskaya.olga@list.ru

https://orcid.org/0000-0001-9954-2667

Чекнёв Сергей Борисович - д-р мед. наук, зам. директора по научной работе, зав. лаб. межклеточных взаимодействий ФГБУ «НИЦЭМ им. Н.Ф. Гамалеи» Минздрава России, Москва, Российская Федерация

E-mail: cheknev@gamaleya.org

http://orcid.org/0000-0002-9512-7148

Санин Александр Владимирович - д-р биол. наук, проф., зав. лаб. клеточного иммунитета, ФГБУ «НИЦЭМ им. Н.Ф. Гамалеи» Минздрава России, Москва, Российская Федерация

E-mail: saninalex@inbox.ru

http://orcid.org/0000-0003-3091-5802

Пронин Александр Васильевич - д-р биол. наук, проф., зам. директора по научной работе ФГБУ «НИЦЭМ им. Н.Ф. Гамалеи» Минздрава России, Москва, Российская Федерация

E-mail: proninalexander@yandex.ru

http://orcid.org/0000-0001-5266-9783
28. Salikhova A.F., Farkhutdinova L.M. Immunological shifting in obesity and their relationship with disorders of carbohydrate metabolism. Medical immunology. 2013; 15 (5): 465-70. (in Russian)

29. Ballak D.B., Stienstra R., et al. IL-1 family members in the pathogenesis and treatment of metabolic disease: focus on adipose tissue inflammation and insulin resistance. Cytokine. 2015; 75 (2): 280-90. DOI: https://doi.org/1016/j.cyto.2015.05.005

30. Silvia de Barros-Mazon S., Marin D.M., de Carvalho C.P., Alegre S.M. Inflammatory and metabolic markers in pre- and posttreatment of obesity. Antiobes. Drug Discov. Dev. 2011; 1: 49-66. DOI: https://doi.org/10.2174/978160805163211101010049

31. Perminova O.M., Volsky N.N., Kudaeva O.T., Goyman E.V., Kozlov V.A. Dyslipidemia and Th1/Th2 ratio at different stages of chronic «graft versus host» reaction development. Immunologiya. 2009; 30 (6): 341-5. (in Russian)

\section{Authors' information}

Tatiana N. Nikolaeva - MD, PhD, Head of the Innate Immunity Lab. N.F. Gamaleya NRCEM of the MOH of Russia, Moscow, Russian Federation

E-mail: tatyananik.55@mail.ru

https://orcid.org/0000-0001-6226-7251

Vyacheslav V. Kozlov - Researcher of the Innate Immunity Lab., N.F. Gamaleya NRCEM of the MOH of Russia, Moscow, Russian Federation

E-mail: hyperslava@yandex.ru

https://orcid.org/0000-0002-0502-4824

Tatiana N. Kozhevnikova - PhD, Researcher of the Cellular Immunity Lab., N.F. Gamaleya NRCEM of the MOH of Russia, Moscow, Russian Federation

E-mail: tatiana140663@gmail.com https://orcid.org/0000-0003-0507-1935

Ekaterina A. Grigorieva - PhD, Researcher of the Innate Immunity Lab., N.F. Gamaleya NRCEM of the MOH of Russia, Moscow, Russian Federation

E-mail: katigr@yandex.ru

https://orcid.org/0000-0001-7811-3740

Olga Yu. Sosnovskaya - PhD, Senior Researcher of the Cellular Immunity Lab., N.F. Gamaleya NRCEM of the MOH of Russia, Moscow, Russian Federation

E-mail: sosnovskaya.olga@list.ru

https://orcid.org/0000-0001-9954-2667

Sergey B. Cheknev - MD, PhD, Deputy Director for Science, Head of the Intercellular Interactions Lab., N.F. Gamaleya NRCEM of the $\mathrm{MOH}$ of Russia, Moscow, Russian Federation

E-mail: cheknev@gamaleya.org

http://orcid.org/0000-0002-9512-7148

Aleksander V. Sanin - Dr.Sci, PhD, Prof., Head of the Cellular Immunity Lab., N.F. Gamaleya NRCEM of the MOH of Russia, Moscow, Russian Federation

E-mail: saninalex@inbox.ru

http://orcid.org/0000-0003-3091-5802

Alexander V. Pronin - Dr.Sci, PhD, Prof., Deputy Director for Science, N.F. Gamaleya NRCEM of the MOH of Russia, Moscow, Russian Federation

E-mail: proninalexander@yandex.ru

http://orcid.org/0000-0001-5266-9783 